\title{
Plasma sex hormone concentrations in men with hypertension treated with methyldopa and/or propranolol
}

\author{
R. G. TAYLOR $\dagger$ \\ M.B., M.R.C.P. \\ B. I. HOFFBRAND $\dagger$ \\ D.M., F.R.C.P.
}

A. J. CRISP†
M.B., M.R.C.P.

A. MAGUire*

B.Sc.

\author{
H. S. JACOBS* \\ M.D., F.R.C.P.
}

$\dagger$ †ypertension Clinic, Whittington Hospital, London N19, and *Departments of Obstetrics and Gynaecology, and Chemical Pathology, St Mary's Hospital Medical School, London W2

\begin{abstract}
Summary
Serum concentrations of $\mathrm{LH}, \mathrm{FSH}$, testosterone and prolactin were measured in patients with hypertension treated with propranolol (34 cases), methyldopa (13 cases), and methyldopa + propranolol (11 cases). The results were compared with those obtained in 18 controls (hospital out-patients). There were no differences in these hormone concentrations in the various groups, and no difference between those complaining of impotence (13 cases) and those with normal sexual function.

Impotence in hypertensive men on treatment with methyldopa cannot be explained by abnormalities in secretion of the reproductive hormones.
\end{abstract}

\section{Introduction}

The prevalence of impotence in men on treatment for hypertension varies in different series but in one study was as high as $43 \%$ (Bulpitt, Dollery and Carne, 1974). Drugs which block adrenergic neurones, such as guanethidine, are believed to affect sexual function by interference with the autonomic nervous system. Drugs of other types, such as methyldopa, propranolol and even diuretics (Stessman and Ben-Ishay, 1980) have also been implicated in producing sexual dysfunction in men but by mechanisms that are uncertain. Since methyldopa can raise serum prolactin concentrations (Steiner et al., 1976) it has been suggested that it may cause impotence by producing hyperprolactinaemia (Leading Article, 1979). The present study was designed to see whether impotence occurring in men receiving treatment for hypertension has a hormonal basis.

\section{Patients and methods}

Men aged 31-65 years under regular review in the hypertension clinic, were divided into 3 groups according to their drug therapy. There were 34 men taking propranolol (mean daily dose $285 \pm 37$ mg (s.e. mean)); 13 men taking methyldopa (1000 $\mathrm{mg} \pm 163 \mathrm{mg}$ ) and 11 taking both drugs (propranolol $735 \pm 109 \mathrm{mg}$, methyldopa $1180 \mathrm{mg} \pm 155 \mathrm{mg}$ ). The numbers in each group taking a thiazide diuretic were $25(74 \%), 12(92 \%)$ and $9(82 \%)$ respectively. The mean duration of treatment in each group was 3 years or more. A control group of 18 hospital outpatients not on any of these drugs was also studied.

The presence of sexual dysfunction, defined as failure of erection or unsatisfactory intercourse, was determined by A.J.C. or R.G.T. by directly questioning each patient personally. Patients taking other drugs believed to disturb sexual function were excluded as was any patient with autonomic neuropathy or previous genito-urinary surgery. Blood was drawn from each patient during the mid-afternoon for measurement of serum creatinine, luteinizing hormone (LH) follicle stimulating hormone (FSH) prolactin and testosterone concentrations. Hormone concentrations were measured by specific radioimmuno assays, using reagents supplied through the Supra-Regional Assay Service.

\section{Results}

One of the control subjects and 13 of the hypertensive patients admitted to sexual dysfunction. When the proportion of patients complaining of impotence in each of the treatment groups was compared with the proportion in the control group complaining of impotence $(5.5 \%)$, there was a statistically significant association with combined treatment with methyldopa and propranolol (Fisher's exact probability $=0.0527$ ). The significance of the association was 
TABLE 1. Clinical and endocrine data (mean \pm s.e. mean) in hypertensive patients and control subjects

\begin{tabular}{|c|c|c|c|c|c|}
\hline & Propranolol & $\begin{array}{c}\text { Propranolol }+ \\
\text { methyldopa }\end{array}$ & Methyldopa & Controls & $F$ ratio* \\
\hline Number & 34 & 11 & 13 & 18 & \\
\hline Age (years) & $49 \pm 1 \cdot 6$ & $55 \cdot 3 \pm 2 \cdot 4$ & $56 \cdot 1 \pm 2 \cdot 4$ & $50 \cdot 5 \pm 2 \cdot 3$ & $2 \cdot 53 \dagger$ \\
\hline Sexual dysfunction $n(\%)$ & $6(18)$ & $3(27)$ & $4(31)$ & 1(6) & \\
\hline Luteinizing hormone (u./l) & $4 \cdot 6 \pm 0 \cdot 3$ & $4 \cdot 5 \pm 0.6$ & $6 \cdot 1 \pm 1 \cdot 1$ & $3 \cdot 8 \pm 0 \cdot 3$ & $2 \cdot 68 \dagger$ \\
\hline Follicle stimulating hormone (u./l) & $4 \cdot 7 \pm 0 \cdot 5$ & $5.5 \pm 0.9$ & $6 \cdot 3 \pm 1 \cdot 1$ & $4 \cdot 8 \pm 1 \cdot 1$ & $0.7 \dagger$ \\
\hline Prolactin $(\mathrm{mu} . / \mathrm{l})$ & $139 \pm 10$ & $198 \pm 40$ & $185 \pm 40$ & $146 \pm 21$ & $1 \cdot 59+$ \\
\hline Testosterone $(\mathrm{nmol} / \mathrm{l})$ & $19 \cdot 9 \pm 1 \cdot 2$ & $20 \cdot 3 \pm 1 \cdot 3$ & $19 \cdot 1 \pm 3 \cdot 0$ & $19 \cdot 3 \pm 1 \cdot 0$ & \\
\hline Creatinine $(\mu \mathrm{mol} / \mathrm{l})$ & $108 \pm 3 \cdot 8$ & $122 \pm 8 \cdot 7$ & $111 \pm 10$ & $93 \pm 3 \cdot 4$ & $4 \cdot 38 \ddagger$ \\
\hline
\end{tabular}

* Analysis of variance, 3 d.f. (treatment) and 72 d.f. (errors); $\dagger=$ not significant; $\ddagger P<0 \cdot 01$.

maintained when the patients taking methyldopa alone were considered (Fisher's exact probability $=0.075$ ). There were no significant differences in mean concentrations of serum gonadotophins, prolactin or testosterone when the 4 groups were analysed (Table 1) or when the 13 hypertensive patients with impotence were compared with those not complaining of sexual dysfunction. Finally, mean serum creatinine concentrations were significantly higher in the 3 treatment groups, compared with the controls $(F=9.68,1$ and 74 d.f., $P<0.001)$. There was, however, no significant difference in creatinine concentrations between the 3 treatment groups.

\section{Discussion}

In this study, the authors found a significant association of treatment with methyldopa with sexual dysfunction, an association that has not been observed by previous workers (Bulpitt and Dollery, 1973). The difference from the findings of Bulpitt and Dollery may be due to different methods of assessment, since those workers detected impotence by a self-administered questionnaire and the present authors interviewed the patients directly. That the methodology may have contributed to the difference in the results is also suggested by the much higher rates of sexual dysfunction reported in the earlier study.

When the mean concentrations of the reproductive hormones were compared by analysis of variance, no differences were detected within any of the treatment groups or between the groups on treatment and the controls. In contrast to the findings of Steiner et al. (1976), these data, thereforg, suggest that chronic treatment with methyldo a does not significantly elevate serum prolactin con centrations. The present authors do not consider that the difference from the results obtained Steiner and colleagues can be explained by the tirfe at which the blood samples were obtained (mis afternoon) since those workers reported that prolactin concentrations remained elevated for up to $7 \mathrm{hr}$ after ingestion of methyldopa.

Finally, when the 13 hypertensive patients cor plaining of impotence were compared with the remaining subjects, no difference in hormone go\& centrations was detected. It is therefore conclieded that sexual dysfunction in hypertensive men treat with the drugs used in this study is not caused by disturbance in the secretion of reproductive howmones, either by the pituitary or by the testis. Prosumably, some central action is involved when treatment with methyldopa is complicated impotence.

\section{References}

BulpitT, C.J. \& Dollery, C.T. (1973) Side effects of hypotensive agents evaluated by a self-administered questiognaire. British Medical Journal, 3, 485.

BulpitT, C.J., Dollery, C.T. \& CARNe, S. (1974) A symptoon questionnaire for hypertensive patients. Journal of Chromic Diseases, 27, 309.

LeAding Article (1979) Drugs and male sexual function. British Medical Journal, 2, 883.

Steiner, J., Cassar, J., Mashiter, K., Dawes, I., Russedr Fraser, T. \& BRECKENRIDGE, A. (1970) Effects of methy dopa on prolactin and growth hormone. British Medica! Journal, 1, 1186.

Stessman, J. \& Ben-Ishay, D. (1980) Chlorthalidone-induces impotence. British Medical Journal, 281, 714. 